\title{
The Level of Reactive Carbonyl Derivatives of Proteins, Malondialdehyde, and Catalase Activity in the Brain of Rats after Therapy Following Chronic Unpredictable Moderate Stress
}

Yelena Valerievna Yepifantseva ${ }^{1 *}$, Mayra Galimzhanovna Abdrakhmanova ${ }^{2}$, Yelena Vladimirovna Pozdnyakova ${ }^{3}$, Polina Sergeyevna Semenikhina ${ }^{1}$, Ruslan Andreevich Belyayev ${ }^{1}$, Tatyana Aleksandrovna Stupina ${ }^{1}$, Mira Beisembayeva ${ }^{1}$, Sergazy Mynzhasarovich Adekenov ${ }^{4}$

${ }^{1}$ Department of Neurology, Neurosurgery, Psychiatry and Rehabilitation, Karaganda Medical University, Karaganda, Kazakhstan; ${ }^{2}$ Department of Neurology, Medical University of Astana, Nur-Sultan, Kazakhstan; ${ }^{3}$ Department of Biological Chemistry, Karaganda Medical University, Karaganda, Kazakhstan; ${ }^{4}$ Laboratory of Pharmacology, Phytochemistry International Scientific and Production Holding JSC, Karaganda, Kazakhstan

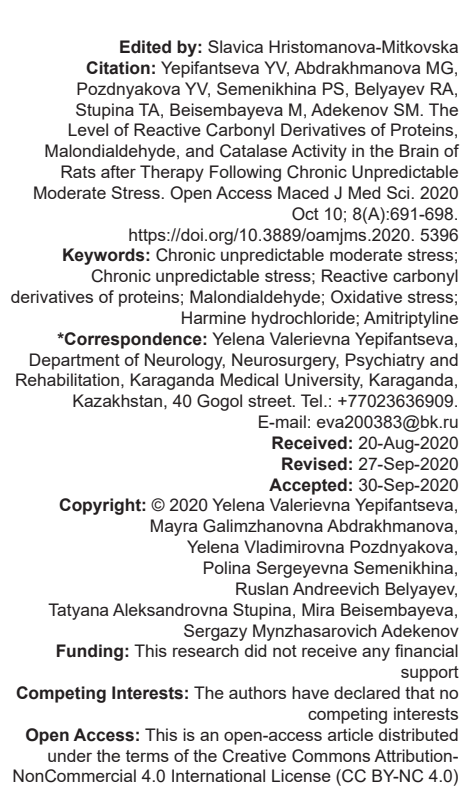

\section{Introduction}

The impact of chronic stress on the human population around the world is of the greatest

\begin{abstract}
BACKGROUND: Understanding the mechanisms of the behavioral disorders' emergence under the influence of chronic stress is the most important aspect of the subsequent development of a strategy for its therapy and prevention. Changes in the oxidative metabolism processes can be decisive in the development of the pathogenetic cascade in the brain Information about these processes can be obtained by studying protein carbonylation, lipid peroxidation, and catalase activity (CA). The complexity of the therapeutic impact in various behavioral disorders implies the search for new pharmacological substances and the study of the previously known drugs' effects based on the available scientific data.

AIM: The aim of the study was to study the reactive carbonyl derivatives of proteins (RCDP), malondialdehyde (MDA), and CA in the brain of rats after therapy following chronic unpredictable moderate stress (CUMS).

METHODS: Forty male outbred rats weighing $450-500 \mathrm{~g}$ were used in this study. For 21 days, all animals were exposed to the diverse stress factors for developing the CUMS. The animals were divided into four groups of 10 rats, each using randomized selection. The rats of one group were euthanized by decapitation with subsequent brain harvesting (Group 4). Remaining three groups of rats were treated with placebo (Group 1), harmine hydrochloride (Group 2), and amitriptyline (Group 3) for 21 days. Upon completion of therapy, all rats were also euthanized by decapitation with subsequent brain harvesting. The levels of RCDP, MDA, and CA were studied in their brain, and after that, we compared the multiple studied indicators in four groups.

RESULTS: The results of the rat brain examinations in four groups showed that RCDP level in Group 2 was significantly lower than in Group $4(p=0.000)$. Similarly, in Group 1, it was lower than in Group $4(p=0.021)$, plus, it did not differ statistically from the harmine hydrochloride group $(p=1,000)$. Indicators of Groups 3 and 4 did not have any significant differences in RCDP level, too, $(p=0.799)$; however, the RCDP level in Group 2 was significantly lower than in Group 3 ( $p=0.040)$. MDA indicators did not show significant differences; however, a tendency for lower values was revealed in Group $1(p=0.233)$ and Group $2(p=0.151)$. CA in Group 4 was lower than that in Group $1(p=0.000)$, Group 2 $(p=0.001)$, and Group $3(p=0.003)$ contemporaneously, while all treatment groups were comparable $(p=1.000)$.

CONCLUSION: The result of exposure to chronic stress can be reproduced with the best quality in the CUMS model. The neurobiological foundations of the model make it possible to assess biochemical markers of oxidative metabolism and evaluate the possibilities of pharmacological correction of stress-induced behavioral disorders. To assess the mechanisms of autoregulation of oxidative metabolism, this study included a placebo group (Group 1), the level of RCDP in which was significantly higher in comparison with Group 3 and Group 4 and slightly lower than in Group 2. In this study, harmine hydrochloride demonstrated activity exceeding amitriptyline, particularly limiting the process of protein carbonylation, not noted for amitriptyline. According to the results of the RCDP assessment in the CUMS model, the process of protein carbonylation can be considered to be one of the significant factors in the deactivation of neurotransmitters. The CA levels determined in all groups allowed us to consider this marker as the most sensitive to the effects of stress, which possibly has an inhibitory effect on catalase, as its activity in al groups after therapy was more than two-fold higher than in animals right after CUMS. We can assume that CA plays an important role in starting the processes of autoregulation of oxidative metabolism. The study was carried out as a part of the implementation of the scientific and technical program No. BR05236584 "Development of new herbal preparations and their pharmacological and clinical studies" (O.0820). (2018-2020) in the priority area, "Life and Health Sciences."
\end{abstract}

interest to researchers. Chronic stress contributes to the formation of a significant number of behavioral reactions similar to endogenous psychopathological syndromes, and the mechanisms for the development of such conditions are continuously studied [1]. The 
most common response to chronic stress exposure is depressive disorder [2]. However, the clinical classification of diseases includes a wide variety of stress-related depressive, anxious, dissociative, somatoform, and mixed reactions associated with impaired adaptation [3]. The type of stress response is assumed to develop depending on individual's biological and personal characteristics.

Research continues on the effects of stress on various biochemical patterns of behavioral disorders. The generation of reactive oxygen species in tissues and organs, probably, due to neurohumoral regulation, plays a significant role in the damaging effect of chronic stress [4]. The accumulation of reactive oxygen species in the brain leads to a disturbance in the balance of the oxidative metabolism and the local homeostasis maintenance processes due to weak antioxidant protection inherent in brain tissues [5]. This results in the macromolecular oxidation of proteins, lipids, and DNA, leading to the formation and accumulation of large molecules capable of inactivating proteasomes [6]. This mechanism is considered to be a pathogenetic variant of the neurodegenerative disease development and could be the cause of explaining the prolonged course of behavioral disorders after the exposure to stress factors ends.

Protein modification under the influence of the increased concentration of reactive oxygen species can happen through carbonylation. The formation of carbonyl derivatives of proteins occurs during the oxidation of amino acid residues as a result of interaction with carbonyl-containing oxidized lipids and through other ways leading to the formation of protein carbonyl. In the long run, after the carbonylation, proteins lose their catalytic functions, thus, significantly reducing their biological activity. Due to high receptor concentration in the brain tissues, oxidative modification of the proteins also leads to a decreased metabolic activity of neurons.

Another indicator that is of interest to researchers is malondialdehyde (MDA), the function of which is still being studied. It is known that MDA, being a degradation product of arachidonic acid and polyunsaturated fats, can act as a signaling molecule, participate in the regulation of gene expression, and cause DNA damage when excessively accumulating in tissues [7].

The study of the processes of antioxidant protection in tissues is most accessible with the evaluation of the catalase activity (CA), an enzyme that destroys toxic hydrogen peroxide. However, the accumulation of hydrogen peroxide under some conditions can also have a protective effect during revascularization [8]. We have not found any data on its effect on the revascularization process in the brain. CA is a marker studied in various pathological conditions, including diseases of the central nervous system. Catalase exhibits the properties of a nonspecific amyloid-binding protein; this fact undoubtedly increases its role in the development and progression of degenerative brain lesions. The neuroprotective effect of catalase is achieved due to its overexpression and ability to directly bind proteins of the amyloid spectrum and prion proteins [9]. We evaluated CA to assess the antioxidant protection in the chronic unpredictable moderate stress (CUMS) model during therapy and to detect the probable inhibitory effect of the studied drugs early.

The therapy of neurotic disorders, including stress-induced disorders, is a problem of current interest in psychiatry. The development of the leading complex of symptoms depends on both neurobiological and neuropsychological factors. Reproducing the stress-generating disorder in an animal experiment is possible only when comparing neurobiological patterns, including biochemical ones. In the literature, there are no data on the dynamics of oxidative metabolism changes when using drugs with an antidepressant effect, due to the dominant importance of behavioral reactions during this type of therapy. However, a wide range of behavioral disorders and individual sensitivity to pharmacological drugs determine the ongoing search for the new agents of combined action with antidepressant and anxiolytic effects. Most of the research is a process of investigating drugs with antidepressant effects in the CUMS model, which is currently considered valid [10].

Harmine hydrochloride is a water-soluble form of the indole alkaloid harmine isolated from an ethanol extract of the Peganum harmala L. roots. Harmine, showing properties of a MAO-B inhibitor and, in high concentrations, also is MAO-A inhibitor, is able to suppress the inactivation of monoamine mediators [11]. Harmine was previously used in the treatment of Parkinsonism but was supplanted with the advent of new antiparkinson drugs [12]. This study of harmine was continued from the standpoint of its antihypoxant, antidepressant, antianxiety, antiparkinsonian, and anticarcinogenic and other types of activity [13], [14], [15], [16]

According to the literature data, there is little information about markers of the oxidative metabolism state such as reactive carbonyl derivatives of protein (RCDP), MDA, and CA, in brain under conditions of chronic unpredictable stress and during the subsequent therapy. There are no data from studies on the effect of harmine hydrochloride on the processes of oxidative metabolism in the brain. Possible further studies of the harmine hydrochloride effect on the oxidative metabolism in brain and high bioavailability of its water-soluble form allow to contemplate it as a promising drug for the correction of stress-induced disorders.

The aim of our study was to examine changes in the levels of RCDP, MDA, and CA in brain of rats after therapy with harmine hydrochloride and amitriptyline following CUMS. 


\section{Methods}

The study of the effects of the psychoactive substance requires the use of an experimental model that reproduces the symptoms of the studied conditions in animals [10]. In our research, a modified "Chronic unpredictable moderate stress" (CUMS) model was used [17], [18]. CUMS is considered to be a reference model and is recommended for use to provoke the emergence of stress-induced behavioral disorders in experimental animals. Based on the reference model, we developed a personalized algorithm, the effectiveness of which in inducing stress associated disorders was assessed in standardized behavioral tests [19], [20].

\section{Selection and description of participants}

Forty male outbred rats weighing 450-500 g were used in this study. The animals were kept under standard laboratory conditions $\left(25 \pm 2^{\circ} \mathrm{C}\right.$, humidity $60-70 \%$ ), five rats per cage, maintaining a $12-\mathrm{h}$ natural day-night cycle with free access to standard food and water. The quarantine and keeping conditions of the animals before the start of the experiment met the established requirements.

\section{Technical information}

Experimental animals were exposed to chronic unpredictable stress for 21 days to form a stress-induced behavioral disorder. After that, the animals were divided by randomization into 4 groups, 10 rats each. Animals of the $4^{\text {th }}$ group were euthanized by decapitation with subsequent harvesting of the brain. The experiment was continued using 30 animals, divided into three groups, which were subjected to a therapeutic effect for 21 days using placebo in the Group 1, harmine hydrochloride in the Group 2, and amitriptyline in the Group 3. On the $43^{\text {rd }}$ day of the experiment, the animals were euthanized by decapitation, followed by a brain harvesting. After removal from the cranium, the brain of the animals was subjected to grinding, freezing, and homogenization procedures for further spectrophotometric analysis.

The study was conducted in accordance with the requirements of the European Convention for the Protection of Vertebrate Animals Used in Experiments and Other Scientific Purposes (Strasbourg, 1986), requirements of GLP OECD, EAEU Rules of Good Laboratory Practice No. 81, order of the Ministry of Health and Social Development of the Republic of Kazakhstan No. 392 dated May 25, 2015. The study was approved by the decision of the Committee on Bioethics of the Karaganda Medical University on June 17, 2019, protocol No. 65.

\section{Experimental procedure for CUMS model}

The stress model was formed in animals during a 21-day period (3 cycles of 7 days each), when all animals were exposed to CUMS according to the scheme presented in Table 1, listing the recommended time for the formation of a behavioral disorder in experimental animals. [18].

\section{Table 1: CUMS model}

\begin{tabular}{|c|c|c|c|}
\hline Day & Type of exposure & $\begin{array}{l}\text { Starting } \\
\text { time }\end{array}$ & Duration \\
\hline 1 & $\begin{array}{l}\text { Narrow cell (limiting the space of the cell by half due } \\
\text { to the installation of an additional partition in the cell) }\end{array}$ & 12.00 & $20 \mathrm{~h}$ \\
\hline 2 & Food deprivation & 8.00 & $24 \mathrm{~h}$ \\
\hline 3 & $\begin{array}{l}\text { Immobilization in a case (animals were placed in } \\
\text { individual cases, which do not deprive them of } \\
\text { the ability to move, but greatly limit the space for } \\
\text { movement) }\end{array}$ & 10.00 & $4 \mathrm{~h}$ \\
\hline 4 & Artificial shading during daylight hours & 6.00 & $15 \mathrm{~h}$ \\
\hline 5 & Water deprivation & 8.00 & $10 \mathrm{~h}$ \\
\hline 5 & Artificial light during night hours & 19.00 & $15 \mathrm{~h}$ \\
\hline 6 & $\begin{array}{l}\text { Full immobilization (animals were placed in individual } \\
\text { canisters, depriving them of the ability to move) }\end{array}$ & 10.00 & $2 \mathrm{~h}$ \\
\hline 7 & Behavioral tests & 10.00 & $\begin{array}{l}8 \mathrm{~h} \text { with } 1 \mathrm{~h} \text { break } \\
\text { between tests }\end{array}$ \\
\hline
\end{tabular}

Upon the formation of the stress-induced disorder model, from the $22^{\text {nd }}$ day, the daily exposure to stress factors was terminated and the experiment continued under standard conditions for the rats.

\section{Behavioral assessments}

Conducting the trial using behavioral tests was part of the stress-induced disorder development model as one of the stress factors. Assessment in behavioral tests was carried out before the start of the experiment and at days 7, 14, 21, 28, 35, and 42. Signs of stress-induced disorder were revealed in animals of all groups, and their severity was evaluated using standard protocols in the "open field test" [21], "the elevated cross-maze test" [22], "tail-hanging test" [23], and "sucrose preference test" [24], however, reporting of the results of the tests is not the purpose of this article. According to the approved procedure, additional stressors were not used on the day of the behavioral testing. A rest period of $1 \mathrm{~h}$ was allowed between tests.

\section{Drug treatment}

After the formation of the model stressinduced disorder from the $22^{\text {nd }}$ day forward, every day at 10.00 , the rats received therapy by intragastric tube administration. Animals of the Group 1 received $2 \mathrm{ml}$ of placebo ( $\mathrm{NaCl} 0.9 \%)$, Group 2-4.5 mg/ $\mathrm{kg}$ individually of harmine hydrochloride, and the Group 3-4.5 mg/kg individually of amitriptyline. The treatment lasted 21 days, as the sources note such duration as the shortest time recommended for the psychotherapeutic effect of the drug to be achieved [25]. 


\section{Spectrophotometric study}

Twenty-four hours after the last dose, all animals were euthanized by decapitation, the skull was opened and the brain harvested. The brain was washed with $0.9 \%$ $\mathrm{NaCl}$ solution, crushed into small pieces, and flooded with liquid nitrogen to preserve its native characteristics until biochemical analysis; after that, the brain was stored in a freezer at $-18^{\circ} \mathrm{C}$. Then, the brain was homogenized in a Teflon homogenizer in $0.1 \mathrm{M}$ phosphate buffer $(\mathrm{pH}$ 7.4 ) and centrifuged while being cold to obtain $10 \% \mathrm{w} / \mathrm{v}$ brain tissue homogenate to determine the parameters of RCDP, MDA, and CA. The resulting samples were pretreated according to the recommended procedures and subjected to spectrophotometric analysis using a PD-303UV digital UV-VIS spectrophotometer, manufactured by APEL, Japan.

\section{Determining RCDPs}

We measured the concentration of RCDP following the well-tested protocol of Arutyunyan et al. (2000) [26]. The assessment method is based on the interaction of oxidized amino acid residues of proteins with 2,4-dinitrophenylhydrazine (2,4-DNPH) with the formation of 2,4-dinitrophenylhydrazones, which are recorded spectrophotometrically. A $1 \%$ solution of streptomycin sulfate was used to precipitate nucleic acids, which are known to be capable of increasing the level of carbonyl compounds. We added 9 volumes of brain homogenate to 1 volume of streptomycin sulfate solution, left the solution for $15 \mathrm{~min}$, then centrifuged it for $10 \mathrm{~min}$ and used the supernatant for analysis.

The resulting material was divided into 2 equal parts. We added $0.5 \mathrm{~mL}$ of a $10 \mathrm{mM}$ solution of 2,4$\mathrm{DNPH}$ in $2 \mathrm{M} \mathrm{HCl}$ solution to the experimental sample and the same amount of $2 \mathrm{M} \mathrm{HCl}$ solution to the control sample. The samples were left at room temperature for $1 \mathrm{~h}$, being shaken occasionally every 10-15 min. Then, we added $0.5 \mathrm{~mL}$ of a $20 \%$ trichloroacetic acid (TCA) solution to both samples and centrifuged them at $11,000 \mathrm{~g}$, decanted the supernatant, and washed the precipitate 3 times with $1 \mathrm{~mL}$ of a mixture of ethanol and ethyl acetate (1:1) to eliminate unreacted 2,4-DNPG and lipid additives. Then, the precipitate was dissolved in $0.6 \mathrm{ml}$ of guanidine solution. To eliminate insoluble components, the liquid was centrifuged for $3 \mathrm{~min}$. The amount of the formed 2,4-DNP-hydrazones was recorded at the maximum adsorption (wavelength $370 \mathrm{~nm}$ ) in comparison with the control sample. Concentration of carbonyl derivatives was calculated using the molar absorption coefficient of $22,000 \mathrm{~mol}^{-1} \mathrm{~cm}^{-1}, \mathrm{RCDP}$ values were given in $\mathrm{nmol} / \mathrm{mL}$.

\section{Determining MDA}

Lipid peroxidation was determined by quantifying the thiobarbituric acid-reactive substances
(Ohkawa et al., 1979). One aliquot (75 $\mu \mathrm{L})$ of homogenized tissue $(0.1 \pm 0.005 \mathrm{~g} / 1 \mathrm{~mL}$ of water) was diluted with Tris-HCl buffer, $\mathrm{pH} 7.4$ (175 $\mu \mathrm{L} ; 0.15 \mathrm{M})$. After $30 \mathrm{~min}$ of incubation at $37^{\circ} \mathrm{C}$, we added $500 \mu \mathrm{L}$ of thiobarbituric acid $(0.3 \%[\mathrm{w} / \mathrm{v}])$ dissolved in TCA (15\% [w/v]). Then, the samples were boiled for $1 \mathrm{~h}$ and centrifuged at $6000 \mathrm{rpm}$ for $15 \mathrm{~min}$. The level of lipid peroxidation was expressed as $\mu \mathrm{mol} / \mathrm{mg}$ of protein of MDA at $540 \mathrm{~nm}$ [27].

\section{Determining CA}

The method of Aebi (1984) was used to determine the activity of catalase in brain tissues homogenate. First, we incubated the homogenate in the reaction mixture containing $0.1 \mathrm{~mL}$ homogenate and $0.85 \mathrm{~mL}$ potassium phosphate buffer $(50 \mathrm{mM}$ and $\mathrm{pH}$ 7.0) at room temperature for $10 \mathrm{~min}$. Then, we launched the reaction by adding $0.05 \mathrm{~mL} \mathrm{H}_{2} \mathrm{O}_{2}$ (30 mM prepared in potassium phosphate buffer, $50 \mathrm{mM}$, and $\mathrm{pH}$ 7.0). A decrease in the absorbance was recorded by a spectrophotometer at an excitation of $240 \mathrm{~nm}$ for $3 \mathrm{~min}$. The specific activity of catalase was calculated as $1 \mu \mathrm{mol} \mathrm{H}_{2} \mathrm{O}_{2}$ decomposed $\mathrm{U} / \mathrm{mg}$ protein [28].

\section{Statistics}

The results were statistically processed using SPSS.Statistics.v22.Multilingual-EQUiNOX (SPSS Inc.) software. Analysis of the obtained data was conducted using descriptive statistics. To assess the studied indicators of oxidative metabolism, multiple comparisons were made across groups using the nonparametric Kruskal-Wallis test ( $\alpha=0.05)$.

\section{Results}

The analysis of descriptive statistics presented in Table 2 made it possible to estimate the values of the studied indicators and the absolute difference between groups based on Me (Q25; Q75). Hence, according to the available data on the Group 4 indicators, after the CUMS model formation, the level of RCDP Me $=0.074$ $(0.070 ; 0.078)$, which exceeds the indicators in all groups receiving therapy, including placebo, by 1.5-2 times. At the same time, the CA in the treatment groups is

Table 2: Descriptive statistics by group

\begin{tabular}{|c|c|c|c|c|}
\hline \multirow[t]{2}{*}{ Indicator } & Me (Q25; Q75) & Me (Q25; Q75) & Me (Q25; Q75) & $\mathrm{Me}(\mathrm{Q} 25 ; \mathrm{Q75})$ \\
\hline & Group 1 & Group 2 & Group 3 & Group 4 \\
\hline RCDP & 0.042 & 0.037 & 0.058 & 0.074 \\
\hline MDA & $\begin{array}{l}(0.041 ; 0.053) \\
0.047\end{array}$ & $\begin{array}{l}(0.033 ; 0.048) \\
0.045\end{array}$ & & $\begin{array}{l}(0.070 ; 0.078) \\
0.055\end{array}$ \\
\hline & $(0.043 ; 0.050)$ & $(0.033 ; 0.048)$ & $(0.049 ; 0.053)$ & $(0.050 ; 0.066)$ \\
\hline CA & $\begin{array}{l}0.503 \\
(0.492 ; 0.559)\end{array}$ & $\begin{array}{l}0.492 \\
(0.462 ; 0.522)\end{array}$ & $\begin{array}{l}0.481 \\
(0.476 ; 0.053)\end{array}$ & $\begin{array}{l}0.232 \\
(0.222 ; 0.243)\end{array}$ \\
\hline
\end{tabular}


2 or more times higher than this indicator in Group 4 $\mathrm{Me}=0.232(0.222 ; 0.243)$. However, the MDA level $\mathrm{Me}=0.055(0.050 ; 0.066)$ does not differ significantly between the groups.

We verified these tendencies by multiple comparisons between groups using the nonparametric Kruskal-Wallis test $(\alpha=0.05)$. Statistically significant differences were accepted at $p \leq 0.05$.

When comparing the RCDP indicators in the rats' brains between four groups, according to the data presented in Table 3, we found that the group receiving harmine hydrochloride therapy (Group 2) had a significantly lower level of RCDP than Group 4 right after stress $(p=0.000)$. Placebo therapy in Group 1 also showed a significantly lower level of RCDP than in Group $4(p=0.021)$ and did not differ from Group 2 of harmine hydrochloride $(p=1,000)$. Indicators of Groups 3 and 4 did not show significant differences in the RCDP level $(p=0.799)$. Plus, the RCDP level in the harmine hydrochloride group (Group 2) was significantly lower than in the amitriptyline group $(p=0.040)$; however, there were no significant differences between the amitriptyline (Group 3) and placebo (Group 1) $(p=0.925)$.

Table 3: RCDP levels in brain in the groups

\begin{tabular}{lllll}
\hline Kruskal-Wallis $\mathrm{H}$ test $(\alpha=0.05) \mathrm{H}(3, \mathrm{n}=40)=19.88 \mathrm{p}=0.000$ \\
\hline RCDP & Group 1 & Group 2 & Group 3 & Group 4 \\
\hline Group 1 & 1.000 & 1.000 & 0.925 & 0.021 \\
Group 2 & 0.925 & 0.040 & 0.040 & 0.000 \\
Group 3 & 0.021 & 0.000 & 0.799 & 0.799 \\
Group 4 & \multicolumn{4}{l}{} \\
\hline \multicolumn{7}{l}{ RCDP: Reactive carbonyl derivatives of protein } \\
\hline
\end{tabular}

The results of the MDA level comparison between the groups, presented in Table 4, did not demonstrate any statistically significant differences. However, a tendency toward a decrease of MDA level was noted in placebo Group $1(p=0.233)$ and harmine hydrochloride Group $2(p=0.151)$ relative to the indicators of the group without therapy (Group 4), while the indicators of the amitriptyline Group 3 and the group without therapy (Group 4) were comparable $(p=1.000)$ and did not differ from each other.

Table 4: MDA levels in brain in the groups

\begin{tabular}{lllll}
\hline \multicolumn{5}{l}{ Kruskal-Wallis $\mathrm{H}$ test $(\alpha=0.05) \mathrm{H}(3, \mathrm{n}=40)=7.846 \mathrm{p}=0.049$} \\
\hline MDA & Group 1 & Group 2 & Group 3 & Group 4 \\
\hline Group 1 & & 1.000 & 0.577 & 0.233 \\
Group 2 & 1.000 & & 0.398 & 0.151 \\
Group 3 & 0.577 & 0.398 & & 1.000 \\
Group 4 & 0.233 & 0.151 & 1.000 & \\
\hline
\end{tabular}

When comparing the indicators of the CA in the rats' brain, shown in Table 5, we noticed the significant differences between the treatment groups and Group 4. Descriptive statistics, showing a twofold increase in CA in the treatment groups, proved significant differences in multiple comparisons: CA in Group 4 was lower than

Table 5: CA levels in brain in the groups

\begin{tabular}{lllll}
\hline \multicolumn{5}{l}{ Kruskal-Wallis $\mathrm{H}$ test $(\alpha=0.05) \mathrm{H}(3, \mathrm{n}=40)=22.55 \mathrm{p}=0.000$} \\
\hline CA & Group 1 & Group 2 & Group 3 & Group 4 \\
\hline Group 1 & & 1.000 & 1.000 & 0.000 \\
Group 2 & 1.000 & & 1.000 & 0.001 \\
Group 3 & 1.000 & 1.000 & & 0.003 \\
Group 4 & 0.000 & 0.001 & 0.003 & \\
\hline CA: Catalase activity & & &
\end{tabular}

that in Group 1 of the placebo drug $(p=0.000)$, Group 2 of harmine hydrochloride $(p=0.001)$, and Group 3 of amitriptyline $(p=0.003)$. However, when comparing the treatment groups between each other, we found no significant differences and the indicators were comparable $(p=1.000)$.

The results of the RCDP evaluation showed that the placebo (Group 1) and harmine hydrochloride (Group 2) groups showed significantly lower values compared to Group 4, whereas this effect was not observed in the amitriptyline group (Group 3). However, the RCDP level in the harmine hydrochloride group (Group 2) was significantly lower than in the amitriptyline group (Group 3). The assumption of the absence of significant changes in MDA in the treatment groups was confirmed; however, there was a trend toward a decrease in MDA values in the placebo (Group 1) and harmine hydrochloride (Group 2) groups. When analyzing the CA levels in brain tissue material comparably, we identified the significant differences between all therapeutic groups and the group of animals that was euthanized immediately after the formation of the stress model (Group 4). There were no differences between the three treatment groups in terms of CA parameters.

\section{Discussion}

The effect of chronic stress on the body's biochemical processes is mediated by the complex interconnections of mental, somatic, and neurohumoral reactions of an individual organism. The most studied model for the reproduction of the psychopathological complex is the CUMS model, which validity and predictive value have been confirmed with decades of experiments; currently, CUMS model is used to assess the antidepressant activity of pharmacological drugs [10]. The use of this model is justified for studying the pathogenetic mechanisms of the depressive disorders development and assessing the antidepressant action of drugs because the model proved to demonstrate a satisfactory response to substances with this type of pharmacological effect. Adaptation disorders arising against the background of chronic stress exposure, in our opinion, fully correspond to the CUMS model, making the confirmation of the major depressive disorder unneeded. Based on the DSM-V definition of depressive disorder with its possible development against the background of increased anxiety, the CUMS model allows to evaluate the anxiolytic effects of the studied drugs. Previously, we published a study of the behavioral reactions of rats, where experimental animals experienced anxiety and depressive reactions, which changed their intensity during therapy [20]. However, the present research 
was aimed at studying the biochemical changes in the brain tissues, which is the basis for the formation of psychopathological syndromes.

We assessed the dynamics of changes in indicators taking into account the presence of the group receiving placebo (Group 1). We were able to use this group to evaluate the autoregulation of biochemical processes in the brain after exposure to chronic stress. The intact group of animals was not used in the experiment for ethical reasons. Harmine hydrochloride was included in the study as a drug with high oral bioavailability, which fundamentally distinguishes it from previously used parenteral forms that reduce patients' compliance with therapy. Beta-carboline compounds are known to act as inverse agonists for the benzodiazepine binding site of the gamma-aminobutyric acid type $A$ receptors and have the effect opposite to anxiolytic benzodiazepines [15]. Beta-carboline alkaloids exhibit a wide range of psychopharmacological effects, binding to benzodiazepine, imidazoline, serotonin, and opiate receptors, as well as inhibiting MAO [11]. Harmine's multidirectional receptor activity suggests its potential effect in stress-induced disorders of various types. At the same time, the study of markers of oxidative metabolism makes it possible to assess the safety of its effect on the brain tissue.

The reference drug in the study was amitriptyline, typically used as a standard drug in the treatment of stress, in particular depressive and anxiety disorders. Amitriptyline, being a tricyclic antidepressant, mediates its action by increasing the synaptic concentration of serotonin and/or norepinephrine in the central nervous system through inhibition of their reuptake by the presynaptic neuronal membrane pump [29]. Amitriptyline was chosen as a reference drug of choice when conducting studies of psychotropic activity because of its well-known effects and short duration of treatment needed to reach high and rapid efficacy.

Our study shows that in the brain of rats treated with harmine hydrochloride, the level of RCDP was twice lower than in the group of rats right after experiencing CUMS and significantly lower than in rats receiving amitriptyline. Based on these data, we can talk about the neuroprotective effect of harmine hydrochloride by limiting the processes of protein carbonylation, which is characteristic of the autoregulatory mechanism, confirmed in the placebo group. However, amitriptyline did not demonstrate a limiting effect on the carbonylation process, which should be considered to be an unfavorable factor due to the prolongation of pathochemical processes in the brain tissue. Perhaps, the therapeutic effect of amitriptyline in anxiety and depressive disorders is mediated by other mechanisms. Yet, the question of the effect of amitriptyline on carbonylation should be contemplated further to exclude the likelihood of accumulation of large molecules, including amyloid proteins, with prolonged use of the drug, which is assumed by current clinical guidelines. It should be noted that a significant difference in the RCDP level in the amitriptyline group was revealed only in comparison with harmine hydrochloride in the absence of significant differences from placebo. Thus, we can conclude about the beneficial effect of harmine hydrochloride on the processes of oxidative modification of proteins. We can assume that the behavioral reactions, developing when exposed to chronic stress, are in part a direct consequence of the oxidative modification of small molecules such as dopamine, epinephrine, norepinephrine, serotonin, and others, leading to deactivation of the brain neurotransmitters. Perhaps, either this mechanism manifests most clearly under the conditions of the unpredictably alternating stress factors, preventing adaptation, or excessively long exposure to the same type of stress leads to maladjustment with depletion of the pool of neurotransmitters.

Existing studies of lipid peroxidation, using MDA as a marker, indicate the activation of lipid peroxidation processes in stress [30]. However, the authors used the combined score of MDA and 4-hydroxyalkenals without specifying the percentage of each marker. According to the results of our study, there were no significant differences in the MDA level between groups, but the tendency toward a decrease of this marker was most pronounced in animals receiving harmine hydrochloride and placebo. The revealed trend demonstrates the absence of the damaging effect of harmine hydrochloride, which activity is comparable to the autoregulation processes and contingently exceeds the effect of amitriptyline. Probably, it is necessary to determine the concentration of MDA in the regions of the brain that is most involved in the development of behavioral disorders, such as the hippocampal and prefrontal regions, as was done by the previously mentioned researchers. Our previous studies showed statistically significant deviations in MDA levels in plasma and erythrocytes of rats with the CUMS model [18]. The use of a different marker in the study of lipid peroxidation processes in the brain may also be recommended.

The assessment of CA confirmed that exposure to chronic stress leads to inhibition of catalase, as the brain of animals immediately after the formation of the CUMS model contained low levels of it. A decrease in $\mathrm{CA}$ and, as a consequence, in antioxidant protection under chronic stress can be a factor in the subsequent progression of the associated pathochemical processes. However, the results obtained in all treatment groups demonstrated a significant increase in CA, which may indicate the restoration of enzyme activity after the cessation of stress. We suggest that catalase reactivation can be considered one of the triggering mechanisms of the neurohumoral homeostasis autoregulation in the brain. The study of CA under conditions of longer chronic stress may be of value in understanding the development of long-term adaptation disorders. 


\section{Conclusion}

The study of the mechanisms involved in the oxidative metabolism shows that biochemical processes in the brain of rats under conditions of chronic stress and after its cessation demonstrate different degrees of involvement. Regulation of reactive oxygen species concentration is supported by the interaction of prooxidant and antioxidant mechanisms. Chronic stress acts as a prooxidant factor that activates protein carbonylation and inhibits CA in the rats' brain. MDA was the least sensitive marker of the oxidative stress, despite the high level of lipid metabolism in the brain. The effect of using harmine hydrochloride was comparable within the studied parameters with placebo, slightly exceeding it in limiting the processes of protein carbonylation. According to the studied markers, harmine hydrochloride is significantly superior to amitriptyline, the influence of which on carbonylation processes requires further study in case of its possible prolongation of the stressogenic effect.

\section{References}

1. Vasilyeva AV, Karavaeva TA, Poltorak SV, Kolesova YP, Platunov AV, Fomicheva MV, et al. Clinical Presentation and Personalized Diagnosis of Neurotic Level Disorders in the Practice of Borderline Psychiatry: Guidelines. Russia: National Medical Research Center for Psychiatry and Neurology; 2018. p. 49.

2. Hammen C. Stress and depression. Annu Rev Clin Psychol. 2005;1:293-319.

PMid: 17716090

3. International Classification of Diseases $\left(10^{\text {th }}\right.$ Revision). Classification of Mental and Behavioral Disorders (Clinical Descriptions and Instructions for Diagnosis). Russia: World Health Organization; 1994. p. 304.

4. Fontella FU, Siqueira IR, Vasconcellos AP, Tabajara AS, Netto CA, Dalmaz C. Repeated restraint stress induces oxidative damage in rat hippocampus. Neurochem Res. 2005;30(1):105-11. https://doi.org/10.1007/s11064-004-9691-6 PMid:15756938

5. Popa-Wagner A, Mitran S, Sivanesan S, Chang E, Buga AM ROS and brain diseases: The good, the bad, and the ugly. Oxid Med Cell Longev. 2013;2013:963520. https://doi. org/10.1155/2013/963520

PMid:24381719

6. Dalle-Donne I, Aldini G, Carini M, Colombo R, Rossi R, Milzani A. Protein carbonylation, cellular dysfunction, and disease progression. J Cell Mol Med. 2006;10(2):389-406. https://doi.org/10.1111/j.1582-4934.2006.tb00407.x PMid: 16796807

7. Ayala A, Muñoz MF, Argüelles S. Lipid peroxidation: Production, metabolism, and signaling mechanisms of malondialdehyde and 4-hydroxy-2-nonenal. Oxid Med Cell Longev. 2014;2014:360438. https://doi.org/10.1155/2014/360438 PMid:24999379

8. Hodara R, Weiss D, Joseph G, Velasquez-Castano JC, Landázuri N, Han JW, et al. Overexpression of catalase in myeloid cells causes impaired postischemic neovascularization. Arterioscler Thromb Vasc Biol. 2011;31(10):2203-9. https://doi. org/10.1161/atvbaha.111.233247

\section{PMid:21799178}

9. Chilumuri A, Odell M, Milton NG. Benzothiazole aniline tetra (ethylene glycol) and 3-amino-1,2,4-triazole inhibit neuroprotection against amyloid peptides by catalase overexpression in vitro. ACS Chem Neurosci. 2013;4(11):1501-12. https://doi.org/10.1021/cn400146a PMid:23968537

10. Willner $P$. The chronic mild stress (CMS) model of depression History, evaluation and usage. Neurobiol Stress. 2016;6:78-93. https://doi.org/10.1016/j.ynstr.2016.08.002 PMid:28229111

11. Herraiz T, González D, Ancín-Azpilicueta C, Arán VJ, Guillén H. Beta-carboline alkaloids in Peganum harmala and inhibition of human monoamine oxidase (MAO). Food Chem Toxicol. 2010;48(3):839-45. https://doi.org/10.1016/j.fct.2009.12.019

PMid:20036304

12. Djamshidian A, Bernschneider-Reif $S$, Poewe W, Lees AJ Banisteriopsis caapi, a forgotten potential therapy for Parkinson's disease? Mov Disord Clin Pract. 2015;3(1):19-26. https://doi.org/10.1002/mdc3.12242

PMid:30713897

13. Shabani SH, Tehrani SS, Rabiei Z, Enferadi ST, Vannozzi GP. Peganum harmala L.'s anti-growth effect on a breast cancer cell line. Biotechnol Rep (Amst). 2015;8:138-143. https://doi. org/10.1016/j.btre.2015.08.007

PMid:28352583

14. Hamid HA, Ramli AN, Yusoff MM. Indole alkaloids from plants as potential leads for antidepressant drugs: A mini review. Front Pharmacol. 2017;8:96. https://doi.org/10.3389/ fphar.2017.00096

PMid:28293192

15. Patel K, Gadewar M, Tripathi R, Prasad SK, Patel DK. A review on medicinal importance, pharmacological activity and bioanalytical aspects of beta-carboline alkaloid "Harmine". Asian Pac J Trop Biomed. 2012;2(8):660-4. https://doi.org/10.1016/ s2221-1691(12)60116-6

PMid:23569990

16. Khadhr M, Bousta D, Hanane EH, El Mansouri L, Boukhira S, Lachkar M, et al. HPLC and GC-MS analysis of Tunisian Peganum harmala seeds oil and evaluation of some biological activities. Am J Ther. 2017;24(6):e706-12. https://doi. org/10.1097/mjt.0000000000000402

PMid:27058575

17. Willner $P$, Scheel-Krüger J, Belzung $C$. The neurobiology of depression and antidepressant action. Neurosci Biobehav Rev. 2013;37(10):2331-71. https://doi.org/10.1016/j. neubiorev.2012.12.007

PMid:23261405

18. Yepifantseva YV, Muravlyova LY, Semenikhina PS, Romanova MA, Seidakhmetova RB, Smagulov AM, et al. The level of reactive carbonyl derivatives of proteins, methylglyoxal, and malondialdehyde in rats experiencing chronic unpredictable moderate stress. Open Access Maced J Med Sci. 2020;8:266-72. https://doi.org/10.3889/oamjms.2020.3986

19. Certificate of the State Register of Rights to Copyright Protected Objects No. 7372. Method for the Formation of Stress-induced Disorders in an Experiment in Animals. Russian: Work of Science; 2019.

20. Yepifantseva YV, Romanova MA, Seidakhmetova RB, Adekenov SM, Pozdnyakova YV, Kitova TT. Influence of harmine hydrochloride on behavioral reactions of rats undergoing a model of stress-induced disorder. Med Ecol. 2020;1(94):77-88. 
21. Kuniishi H, Ichisaka S, Yamamoto M, Ikubo N, Matsuda S, Futora $\mathrm{E}$, et al. Early deprivation increases high-leaning behavior, a novel anxiety-like behavior, in the open field test in rats. Neurosci Res. 2017;123:27-35. https://doi.org/10.1016/j. neures.2017.04.012

PMid:28450152

22. Bakhtiyarova SK, Kapysheva UN, Ablaykhanova NT, Baimbetova AK, Zhaksymov BI, Korganbayeva AA, et al. Behavior of animals in various tests. Int J Appl Basic Res. 2017;8-1:92-96.

23. Zhu W, Gao Y, Chang CF, Wan JR, Zhu SS, Wang J. Mouse models of intracerebral hemorrhage in ventricle, cortex, and hippocampus by injections of autologous blood or collagenase. PLoS One. 2014;9(5):e97423. https://doi.org/10.1371/journal. pone.0097423

PMid:24831292

24. Fernandez JW, Grizzell JA, Philpot RM, Wecker L. Postpartum depression in rats: Differences in swim test immobility, sucrose preference and nurturing behaviors. Behav Brain Res. 2014;272:75-82. https://doi.org/10.1016/j.bbr.2014.06.041 PMid:24983658

25. Pacher P, Kecskemeti V. Trends in the development of new antidepressants. Is there a light at the end of the tunnel? Curr Med Chem. 2004;11(7):925-43. https://doi. org/10.2174/0929867043455594
PMid: 15078174

26. Arutyunyan AV, Dubinina EE, Zybina NN. Methods for Assessing Free Radical Oxidation and the Antioxidant System of the Body, Guidelines. Russia: PCF Foliant; 2000. p. 104.

27. Cabrera-Pérez LC, Padilla-Martínez II, Cruz A, Mendieta-Wejebe JE, Tamay-Cach F, Rosales-Hernández MC. Evaluation of a new benzothiazole derivative with antioxidant activity in the initial phase of acetaminophen toxicity. Arab J Chem. 2019;12(8):387182. https://doi.org/10.1016/j.arabjc.2016.02.004

28. Vani JR, Mohammadi MT, Foroshani MS, Rezazade E. Evaluation of the neuroprotective and antioxidant effects of Dorema aucheri extract on cerebral ischaemia-reperfusion injury in rats. Pharm Biol. 2019;57(1):255-62. https://doi.org/10. 1080/13880209.2019.1597132

PMid:30957616

29. Amitriptyline Information. Available from: https://www.drugs. com/ppa/amitriptyline.html. [Last accessed on 2020 Aug 06].

30. Herbet M, Korga A, Gawrońska-Grzywacz M, Izdebska M, Piątkowska-Chmiel I, Poleszak E, et al. Chronic variable stress is responsible for lipid and DNA oxidative disorders and activation of oxidative stress response genes in the brain of rats. Oxid Med Cell Longev. 2017;2017:7313090. https://doi. org/10.1155/2017/7313090

PMid:29085557 